\title{
Cobalt spinel via solution combustion synthesis as an ammonia sensing material
}

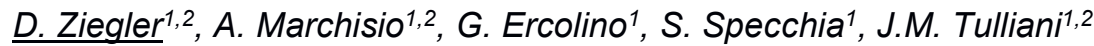 \\ 1 Politecnico di Torino, Department of Applied Science and Technology, Corso Duca degli Abruzzi, \\ 24, 10129 Torino, Italy, \\ 2 INSTM R.U PoliTO-LINCE Laboratory, Corso Duca degli Abruzzi, 24, 10129 Torino, Italy, \\ daniele.ziegler@polito.it
}

\begin{abstract}
:
Nano-crystalline cobalt oxide $\left(\mathrm{CO}_{3} \mathrm{O}_{4}\right)$ was prepared by solution combustion synthesis (SCS) and used as ammonia sensing material. The obtained powder was characterized by laser granulometry, thermal analysis, X-ray diffraction, X-ray Photoelectron Spectroscopy, nitrogen adsorption (B.E.T -Brunnauer, Emmet, Teller- technique), Raman spectroscopy, field emission scanning electron microscopy and transmission electron microscopy. Sensors were screen-printed onto a-alumina substrates with platinum interdigitated electrodes and fired at $700^{\circ} \mathrm{C}$ for $1 \mathrm{~h}$ in air, after drying overnight. The sensor's response $(R)$ was defined as the ratio between the impedance of the film under gas exposure at the equilibrium and the impedance under dry air and was measured in the range $150^{\circ} \mathrm{C}-250^{\circ} \mathrm{C}$ under $1-$ 50 ppm of $\mathrm{NH}_{3}$. Response time and recovery time (e.g., the times taken by the sensor to attain $90 \%$ of total impedance change from its initial impedance value) were also determined. Best results were obtained at $225^{\circ} \mathrm{C}$, with $\mathrm{R}$ equal to 1.83 under $50 \mathrm{ppm}$ exposure to $\mathrm{NH}_{3}$.
\end{abstract}

Key words: Cobalt oxide, sol gel combustion synthesis, p-type semiconductor, ammonia detection, screen printing technique.

\section{Introduction}

Ammonia is a primary eye and upper respiratory tract irritant mainly generated when manufacturing nitrogenous fertilizers and other chemical substances. Thus, this gas is also widely used as a refrigerant [1]. The TimeWeighted Average (TWA) for ammonia over $8 \mathrm{~h}$ should not exceed $25 \mathrm{ppm}$ and the short-term exposure over $15 \mathrm{~min}$ is limited to $25-35 \mathrm{ppm}$ [1]. Therefore, it appears essential to develop ammonia sensors with fast response times, good selectivity, low detection limit, low power consumption and cheap for practical applications. Chemo-resistive gas sensors based on metal oxide semiconductors (MOSs) have been deeply investigated for the detection of toxic and explosive gases, due to their ease of operation, low cost and high sensitivity [2]. Among them, p-type MOSs with strong catalytic ability and high solubility of oxygen can be adopted effectively to produce highperformance gas sensors [3]. $\mathrm{CO}_{3} \mathrm{O}_{4}$ is known as a typical p-type semiconductor gas sensing material with a strong catalytic activity for the oxidation of reducing gases due to multiple possible oxidation states of Co. However, up to now it has not been widely investigated studied for ammonia detection at ppm level.

\section{Materials and methods}

The cobalt spinel powder was synthesized by SCS using glycine $\left(\mathrm{NH}_{2} \mathrm{CH}_{2} \mathrm{COOH}\right)$ as an organic fuel and cobalt nitrate $\left(\mathrm{Co}\left(\mathrm{NO}_{3}\right)_{2}{ }^{*} 6 \mathrm{H}_{2} \mathrm{O}\right)$ as a cobalt precursor and an oxidizer, with an amount of organic fuel with respect to the stoichiometric amount $(\Phi)$ of 0.25 [4]. All reagents were purchased from Sigma-Aldrich (Milan, Italy; $\geq 98 \%$ of purity). After sol gel autocombustion synthesis, the powder was calcined at $700^{\circ} \mathrm{C}$ for 30 minutes in air. Sensors were prepared by screen-printing the spinel powder onto a-alumina substrates (Coors Tek, Golden, CO, USA, ADS-96, 96\% alumina, $0.85 \mathrm{~cm} \times 1.7$ $\mathrm{cm}$ ) with platinum interdigitated electrodes (ESL 5545, King of Prussia, PA, USA). The sensors were then dried at $80^{\circ} \mathrm{C}$ overnight and fired at $700^{\circ} \mathrm{C}$ in air for $1 \mathrm{~h}\left(2^{\circ} \mathrm{C} / \mathrm{min}\right.$ heating and cooling ramps). Sensors were subsequently tested in a home-made system where ammonia was diluted with synthetic air by means of flow meters (Teledyne Hastings Instruments HFM 300 controller and flow meters HFC 302, Teledyne Hastings, Hampton, VA, USA) in a 
constant air flow of $1000 \mathrm{sccm}$ (standard cubic centimeters). The sensors were first tested towards ammonia $50 \mathrm{ppm}$ at different temperatures (in the range from 150 to $250^{\circ} \mathrm{C}$ ), for evaluating the optimum working temperature. Then, different ammonia's concentrations (between 1 and $50 \mathrm{ppm}$ ) were investigated at the optimum temperature of $225^{\circ} \mathrm{C}$.

\section{Results and discussion}

The XRD pattern of the cobalt oxide nanopowder confirms the formation of the cubic $\mathrm{CO}_{3} \mathrm{O}_{4}$ phase (JCPDF card $\mathrm{n}^{\circ} 42-1467$ ), as also shown by XPS results.

Figure 1 displays the sensor response at different temperatures. $\mathrm{Co}_{3} \mathrm{O}_{4}$ sensors behave as p-type semiconductors and their impedance increased from about 1 to $13 \mathrm{k} \Omega$ under dry air up to $1.2-17 \mathrm{k} \Omega$ when exposed to ammonia 50 ppm respectively at 250 and $150^{\circ} \mathrm{C}$ (Table 1 ). Considering the sensor's response as well as, the response and recovery times, the optimum working temperature was equal to $225^{\circ} \mathrm{C}$ as reported in Figure 1 and Table 1.

According to IUPAC definition, the sensitivity of the sensor can be determined from the slope of the curve $\mathrm{R}=\mathrm{f}\left(\left[\mathrm{NH}_{3}\right]\right)$. The response of the sensor is almost linear $\left(R^{2}=0.9845\right)$ in the investigated ammonia concentrations (Figure 2) and the sensitivity is equal to $0.0147 \mathrm{ppm}^{-1}$.

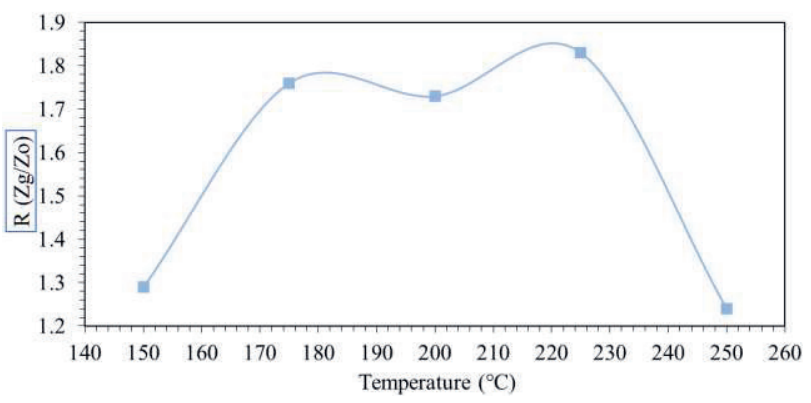

Fig. 1. Sensor film response at different operating temperature $\left(150-250^{\circ} \mathrm{C}\right)$ under $50 \mathrm{ppm} \mathrm{NH}_{3}$ in synthetic air.

Tab. 1: Change of $\mathrm{Co}_{3} \mathrm{O}_{4}$ film impedance at different $T$ under dry air and 50 ppm of ammonia.

\begin{tabular}{|c|c|c|c|}
\hline $\mathrm{T} /{ }^{\circ} \mathrm{C}$ & $\mathrm{Zo}(\mathrm{k} \Omega)$ & $\mathrm{Zg}(\mathrm{k} \Omega)$ & $\mathrm{R}(\mathrm{Zg} / \mathrm{Zo})$ \\
\hline 150 & 13.19 & 17.07 & 1.29 \\
\hline 175 & 5.36 & 9.42 & 1.76 \\
\hline 200 & 1.82 & 3.16 & 1.73 \\
\hline 225 & 1.83 & 3.35 & 1.83 \\
\hline 250 & 0.96 & 1.17 & 1.24 \\
\hline
\end{tabular}

The response and recovery time at $225^{\circ} \mathrm{C}$ under $50 \mathrm{ppm}$ of ammonia were around 1 minute and 6 minutes and 36 seconds, respectively. These features can be reasonably tolerated for some practical applications, like in the monitoring of soil ammonia emissions.

These results are extremely encouraging and support the exploitation of cobalt oxide as ammonia sensing material. Cross-sensitivity tests towards humidity, humidity $+\mathrm{NH}_{3}, \mathrm{CH}_{4}$, ozone, $\mathrm{CO}$ and $\mathrm{CO}_{2}$ will be performed from now on.

\section{References}

[1] https://www.cdc.gov/niosh/pel88/7664-41.html. Visited on February 19th 2018.

[2] N. Barsan, D. Koziej, U. Weimar, Sensors and Actuators B: Chemical 121, 18-35 (2007); doi: 10.1016/j.snb.2006.09.047

[3] H.-J. Kim, J.-H. Lee, Sensors and Actuators B: Chemical 192, 607-627 (2014); doi: 10.1016/j.snb.2013.11.005

[4] G. Ercolino, P. Stelmachowski, A. Kotarba, S. Specchia, Topics in Catalysis 60, 1370-1379 (2017); doi: 10.1007/s11244-017-0826-9

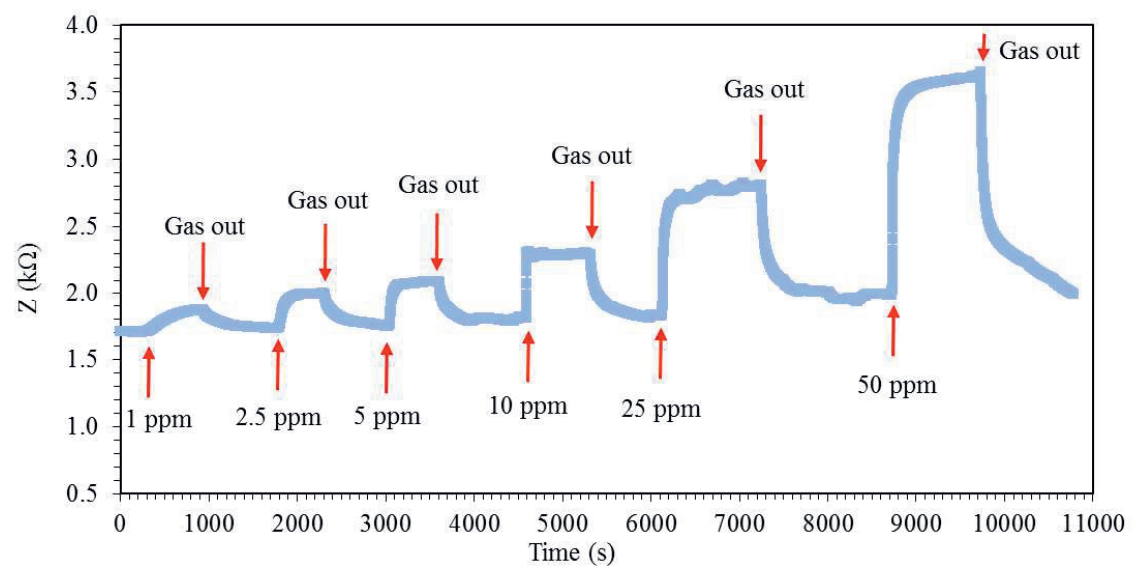

Fig.2. Impedance variations under different ammonia concentrations (1, 2.5, 5, 10, 25 and 50 ppm) at $225^{\circ} \mathrm{C}$. 